\title{
Civilidade e técnicas de si como conceitos para análise sociológica das moralidades
}

\author{
Alyson Thiago Fernandes Freire ${ }^{1}$ \\ Simone Magalhães Brito ${ }^{2}$
}

\section{Resumo}

Com o objetivo principal de buscar instrumentos teóricos para uma abordagem da experiência moral que articule moralidade e poder, este trabalho pretende discutir, numa perspectiva de síntese, os conceitos de civilidade e técnicas de si, do sociólogo alemão Norbert Elias e do filósofo francês Michel Foucault, respectivamente. Tendo em mente o desenvolvimento da pesquisa na sociologia da moral, tentamos demonstrar como esses conceitos abrem a relação mediada dos indivíduos consigo mesmos, com sua subjetividade, emoções e atitudes, para o plano de uma análise sociológica orientada por duas coordenadas: 1) Processos de mudança social via transformação e ruptura de grandes códigos e ethos, e; 2) Constituição do sujeito através de modos de autocompreensão e de práticas morais vividas pelos indivíduos e grupos.

\section{Palavras-chave}

Sociologia da moralidade. Moral. Norbert Elias. Michel Foucault.

\begin{abstract}
With the search for theoretical instruments for an approach of the moral experience that articulates morality and power as the main objective, this paper intends to discuss, in a perspective of synthesis, the concepts of civility and technologies of the self from the German sociologist, Norbert Elias, and the French philosopher, Michel Foucault, respectively. Having in mind the research development in the sociology of the morals, we try to demonstrate how these concepts open the mediated relationships of the individuals with themselves, with their subjectivity, emotions and actions, to the plain of a sociological analysis oriented by two coordinates: 1) Processes of social change through transformation and rupture of important codes and ethos, and 2) The constitution of an individual through the ways of self-understanding and the moral practices experienced by individuals and groups.
\end{abstract}

\section{Keywords}

Sociology of morality. Morals. Norbert Elias. Michel Foucault.

1 Professor de Sociologia do IFRN. E-mail: alyson.freire@ifrn.edu.br.

2 Professora do Departamento de Ciências Sociais e da Pós-Graduação em Sociologia da UFPB. E-mail: simonebritto@hotmail.com. 


\section{Introdução}

A chamada nova sociologia da moral é um campo emergente ainda em busca de um lugar próprio na ordem das especialidades sociológicas. É verdade que o fenômeno da moralidade não é exatamente uma novidade na sociologia. Ele está presente, como bem se sabe, desde os primeiros trabalhos sociológicos, entre os quais, certamente, destacam-se os de Emile Durkheim, Max Weber e Talcott Parsons. A nova sociologia da moral constitui, contudo, um esforço renovado de abordagem e explicação da problemática da moralidade e dos valores ${ }^{3}$. Ela é um campo "redescoberto" (McCAFFREE, 2016) que emerge a partir dos fins dos anos 1980 e começo dos anos 1990, e encontra-se, ainda, como uma subárea em pleno desenvolvimento (HITLIN; VAISEY, 2013).

A pluralidade de enfoques teóricos e a abrangência de seu léxico conceitual, que acolhe uma variedade de aportes oriundos das mais diversas tradições sociológicas e filosóficas, exprimem esse estado não-consolidado e nãoautorreferente $^{4}$. O que, ao contrário de uma fraqueza epistemológica ou barreira, nos parece um convite e abertura à exploração criativa e à busca de subsídios e sínteses teóricas diversas. Como um campo em franco e rápida maturação, a nova sociologia da moral é um empreendimento que ainda está forjando e experimentando os seus instrumentos conceituais e categorias analíticas para consolidar objetivos mais compartilhados e superar dificuldades terminológicas ${ }^{5}$.

No Brasil, podemos observar na recente produção antropológica e sociológica um amplo leque de inspirações teóricas e esforços metodológicos na investigação da problemática dos valores e das moralidades. Referências

\footnotetext{
3 Para Hitlin e Vaisey (2010), a "novidade" da nova sociologia da moral está menos no "objeto" e mais na abordagem. Em vez da preocupação acerca do papel dos valores na internalização, integração e consenso social e de uma abordagem macrossociológica, a nova sociologia da moral se volta mais para um tratamento multidimensional, microssociológico e estratificado da vida moral.

${ }^{4}$ Na sociologia da moral, são múltiplos os conceitos empregados para a abordar o fenômeno moral de uma perspectiva sociológica: "gramática moral", "sentidos de justiça", "valores", "economia moral", "ação ética", "reconhecimento", "fronteiras simbólicas", "sacralidade", entre outros. Não é por acaso que Hitlin e Vaisey consideram que, na verdade, existem "muitas sociologias da moral", e não propriamente uma sociologia da moral (HITLIN; VASEY, 2013, p. 54).

${ }^{5}$ Para um balanço e revisão bibliográfica acerca da produção em sociologia da moral, ver o capítulo "Sociologia da moral: temas e problemas" In. FAZZI, Rita de Cássia; LIMA, Jair Araújo. Campos das Ciências Sociais: figuras do mosaico das pesquisas no Brasil e em Portugal. São Paulo. Ed. Vozes, 2020, p. 481-497.
} 
clássicas e orientações contemporâneas das teorias antropológica e sociológica estão presentes, com rigor e originalidade, nos trabalhos de vários dos mais importantes nomes da produção nacional ${ }^{6}$. É o caso das pesquisas de Roberto Cardoso de Oliveira, Luís Roberto Cardoso de Oliveira, Claudia Fonseca e Patrice Schuch, autores mais vinculados à antropologia, e, por sua vez, mais associados à ciência fundada por Durkheim, cabe mencionar Simone Brito, Raquel Weiss, Alexandre Werneck, Jussara Freire e Carlos Eduardo Freitas.

A sociologia da moral contemporânea tem como uma de suas principais características, portanto, o espírito de abertura e de ampliação do tema da moralidade, das normas e dos valores para abarcar uma gama mais diversificada de comportamentos, atividades e relações da experiência das pessoas. Não somente no sentido de multiplicar as formas de "desnaturalizar" o universo das moralidades, mas de integrá-lo, teórica e empiricamente, a outras dimensões analíticas e esferas da ação social, tal como o campo político e jurídico, as relações e instituições de mercado, a identidade pessoal, as desigualdades sociais, as políticas públicas, os hábitos alimentares, entre outros mais (ABEND, 2013).

Nesse sentido, uma outra motivação nos impulsionou a escrever este artigo: o déficit teórico da nova sociologia da moral quanto ao lugar das lógicas de poder e dominação na estruturação dos valores e na própria experiência moral dos sujeitos ${ }^{7}$. Sustentamos a relevância e necessidade de uma articulação teórica mais direta em direção à temática do poder e da dominação no campo da moralidade e dos valores, e que, também, se coloque como alternativa às perspectivas dominantes que já trilham essa seara na sociologia, tais como as que se inspiram na sociologia bourdieusiana do poder simbólico, como os trabalhos de Michele Lamont $(1994,2000)$, na teoria do reconhecimento de Axel

\footnotetext{
${ }^{6}$ A diversidade teórica, metodológica e temática nacional pode ser constatada no dossiê Sociologia e Antropologia da moral, publicado pela Revista Brasileira de Sociologia das Emoções (RBSE, v.12, n.36) em 2013, pela coletânea de artigos Pensando bem: estudos de sociologia e antropologia da moral, organizado por Luís Roberto Cardoso de Oliveira e Alexandre Werneck (2014) e, mais recentemente, pelo livro organizado por Theophilos Riofiotis e Jean Segata (2019), Políticas etnográficas no campo da moral.

7 No campo da antropologia da moral, poder e moralidade têm sido estudados e abordados de maneira mais frequente e articulada. As pesquisas de Didier Fassin $(2011,2013)$ acerca da razão humanitária e da produção da ordem, assim como os estudos de Akhil Gupta (2012) acerca do inter-relacionamento entre tecnologias de governo e valores morais no cotidiano da Índia contemporânea, são exemplares do potencial científico e crítico de se pensar os nexos entre moralidade e poder de maneira não redutora. Ambos os autores estão, inclusive, entre as referências de fundamentação da pesquisa de Simone Brito (2019) acerca da economia moral da auditoria pública e práticas de transparência e controle da corrupção.
} 
Honneth e, por último, na sociologia pragmática francesa derivada dos estudos de Luc Boltanski e Laurent Thevenot (1991).

A nosso ver, dois conceitos podem ser valiosos e analiticamente fecundos para o duplo propósito que anima o nosso esforço, quais sejam: o conceito de civilidade e o conceito técnicas de si, elaborados e empregados, respectivamente, por Norbert Elias e Michel Foucault.

Com base nesses conceitos, este trabalho busca enfrentar o déficit em relação ao poder sem subsumir a moralidade à condição de acessório ou, menos ainda, de disfarce da dominação. Seguimos a orientação contemporânea de pensar a moralidade de maneira relacional e, também, a perspectiva de elaboração de sínteses teóricas, uma das forças motrizes da generatividade da produção de conhecimento na teoria sociológica contemporânea (ALEXANDER, 1987). Por isso, concentramo-nos mais no empenho de laborar instrumentos analíticos para abordar as moralidades do que na construção de teorias gerais sobre a natureza da moralidade.

Dito isso, passemos aos autores e conceitos a serem examinados. Para compreender a singularidade da construção histórico-cultural do Ocidente, a sociologia figuracional dos processos civilizadores de Norbert Elias (1993, 1994) e a genealogia dos modos de subjetivação de Michel Foucault (1984) assumem, com centralidade, o problema dos liames entre moralidade (códigos, lógicas de valores, práticas de estilização da conduta ética) e poder (formas de sujeição, autocontrole e desigualdade). Em ambos, a moral não é entendida como uma totalidade abstrata e genérica, redutível ao "social", nem é sinônimo de hábitos e costumes socialmente aprovados. Trata-se mais da moral enquanto um feixe de práticas históricas, preocupações normativas e valores fincado nas condições de existência e experiências de camadas sociais particulares cuja finalidade está voltada para a construção do sujeito e de suas relações com o mundo, o corpo, os outros e consigo próprio.

A despeito disso, Norbert Elias e Michel Foucault ainda não foram devidamente avaliados teoricamente acerca das contribuições de seus valiosos recursos analíticos para a sociologia da moral. Dentre seus aportes, pretendemos destacar dois conceitos para avançar alguns passos nessa situação: o de civilidade e o de técnicas de si. 


\section{Civilidade}

O termo civilidade carrega um caráter ambíguo, podendo significar tanto práticas cotidianas de polidez quanto "a condição de organização mais desejada pela sociedade humana: a civilização, o oposto da barbárie" (THOMAS, 2018, p. xv). Algumas vezes, o primeiro sentido é entendido como uma espécie de frivolidade ou ritual vazio. Contudo, é preciso estabelecer logo de início que as regras de cortesia, como o próprio termo implica, eram o tipo de contrato social que organizava as cortes europeias durante a idade média e, portanto, não se estabeleceram como atos gratuitos, gentileza ou consideração, mas com a regulação dos modos de deferência ou submissão numa organização social marcada por diferenças profundas de poder e prestígio. As maneiras e regras que organizavam a vida na corte eram "documentações literais da existência social, ou seja do lugar que o indivíduo ocupava na hierarquia da sociedade de corte" (ELIAS, 2001, p. 111).

A predominância dos critérios financeiros para hierarquização na sociedade contemporânea dificulta que se compreenda a organização das sociedades aristocráticas e, principalmente, como o planejamento das estratégias de comportamento e a modulação das emoções eram fundamentais para ampliação do poder ligado ao status e prestígio. Uma vez que, para Elias, uma das questões centrais da sociologia é descobrir como e por que os indivíduos estão ligados entre si, constituindo figurações particulares, os estudos sobre a cortesia precisam ser entendidos como uma investigação sistemática das lógicas e transformações nas relações de interdependência durante o processo de formação dos Estados-nacionais.

O segundo aspecto da ideia de civilidade - a projeção do Ocidente de uma sociedade ideal - traz ainda mais problemas para a compreensão da perspectiva eliasiana. Para a maioria de seus críticos, interpretar a transição das sociedades de corte para democracias modernas através da ideia de controle da violência é um projeto refutado pela história do século XX. O melhor exemplo dessa crítica talvez seja Bauman, que entende a teoria eliasiana do processo civilizador como um elogio da autoimagem do Ocidente, uma tentativa de naturalização dos padrões e códigos resultantes do imperialismo europeu e, especialmente, uma sociologia que justificava os mecanismos institucionais de reprodução da violência. Uma vez que o problema da civilidade foi identificado como uma tentativa de explicação do fim da violência (BAUMAN, 1998, p. 31), tivemos uma espécie de acordo disciplinar sobre a inutilidade de seu estudo. 
Entendemos que, quando afirma que a ideia de civilização "expressa a consciência que o Ocidente tem de si mesmo" (ELIAS, 1994, p. 25), Elias aponta o horizonte de valores a ser pesquisado ou o sentido principal organizando as práticas ditas virtuosas na formação das sociedades europeias. Mas o posicionamento de Bauman reflete uma postura mais ou menos comum no campo: o estudo do processo civilizador é visto como uma afirmação do evolucionismo generalizado" (GIDDENS,1989, p. 196) e de seu valor moral superior. Esse debate político e normativo sobre o problema civilizacional não é novo, desde a leitura de Kant sobre Rousseau até Freud, os problemas relacionados à transformação da experiência moral resultantes das lógicas de diferenciação foram pensados como o problema dos rumos da civilização (RUNDELL; MENNELL, 1998).

Contudo, a tentativa de analisar sociologicamente as formas de civilidade, relacionando práticas e lógicas de interação em público com o desenvolvimento do poder dos Estados nacionais abre caminho para uma concepção de civilidade e civilização muito distintas daquela estabelecida na autoimagem do Ocidente. Leituras como as de Bauman e Giddens não enxergam, com efeito, o elemento inovador na pesquisa eliasiana, porque não levam em consideração, no momento que foi escrita, a sua guerra às filosofias do espírito alemão, nem a ironia na matéria utilizada para tratar da civilização: as pulsões e os fluidos corporais. Ao identificar o problema sociológico dos ideais de civilidade e civilização com um elogio do evolucionismo, esses autores desconsideram toda potência nietzscheana presente na tensão entre a grandiosidade das imagens de civilização e a mesquinhez de suas práticas.

Desse modo, interessa perceber os desafios de se interpretar o projeto éticopolítico da civilização e civilidade através de uma sociologia empírica. As críticas à sociologia figuracional costumam desconsiderar como é radical a tentativa de traduzir o debate sobre a moralidade mais elevada em regras de controle do corpo e na produção de uma autoimagem satisfatória. Enquanto Alfred Weber discutia o elemento de "redenção espiritual" presente na arte e nos ideais de cada época como elementos do processo civilizador, Norbert Elias, por sua vez, lê esse processo como uma determinação irracional ou compulsão - como uma compulsão externa/interpessoal se transforma numa compulsão interna/individual. Com isso, a possibilidade ou superioridade moral da civilização é posta em suspensão: 
Jamais se pode dizer com absoluta certeza que os membros de uma sociedade são civilizados. Mas, com base em pesquisas sistemáticas, calcadas em evidência demonstrável, cabe dizer com alto grau de certeza que alguns grupos se tornaram mais civilizados, sem necessariamente implicar que é melhor ou pior, ou tem valor positivo ou negativo, tornarse mais civilizado (ELIAS, 1994, p. 221).

A partir disso, nossa perspectiva é que O Processo Civilizador é uma resposta sociológica a um dos problemas centrais do pensamento alemão: o problema do progresso moral na História. Quando lido no contexto dos debates de sua época, essa perspectiva sobre processo civilizador é muito mais uma crítica das pretensões imperialistas, dos modos de legitimação da violência estatal e dos ressentimentos do que um elogio da evolução da vida moral.

\section{Autocontrole}

Como já enfatizamos, cortesia e civilidade não são simples atos amigáveis. $\mathrm{O}$ seu desenvolvimento como um conjunto de regras de organização das ações está ligado à produção de equilíbrio e valor nas disputas que se desenvolviam na sociedade de corte e, posteriormente, na sociedade parlamentar. As regras de cortesia não surgem simplesmente de formas de consideração mútua entre as aristocracias medievais, mas como uma forma pragmática de estabelecimento de contratos:

O mecanismo da etiqueta e do cerimonial de corte não se restringia a sujeitar os passos de cada pessoa singular ao controle do soberano autocrata. Ele tornava simultaneamente visíveis centenas de cortesãos, funcionando em certa medida como um mecanismo de sinalização, em que cada vontade própria, cada rebeldia, cada erro de uma pessoa em particular, porque incomodava muito ou pouco os outros e afetava suas chances de prestígio, tornava-se publicamente visível e, passando por uma série de articulações intermediárias, acabava chegando ao rei (ELIAS, 2001, p.146).

A partir do estudo da sociedade de corte francesa, Elias demonstrou como a inexistência de um monopólio central da violência (ao permitir que os indivíduos estejam mais sujeitos a rompantes, caprichos e incertezas) afeta a extensão das cadeias de dependência, personalizando-as. A divisão entre aliados e inimigos apresenta uma clara limitação à extensão das redes de interação devido ao alto custo para os indivíduos que precisem estabelecer 
algum tipo de competição ou confiança. Desse modo, a mudança civilizadora ocorre num sentido específico:

A moderação das emoções espontâneas, o controle dos sentimentos, a ampliação do espaço mental além do momento presente, levando em conta o passado e o futuro, o hábito de ligar os fatos em cadeias de causa e efeito -todos esses são distintos aspectos da mesma transformação de conduta, que necessariamente ocorre com a monopolização da violência física e a extensão das cadeias da ação e interdependência social (ELIAS, 1993, p. 198).

Os processos de monopolização da força física pelo Estado permitem interações menos tensas e "um autocontrole mais desapaixonado" (ELIAS, 1993, p. 201). Não é que não houvesse autocontrole nas sociedades guerreiras, nestas " poderia ser instilado um autocontrole extremo para suportar a dor, mas ele seria complementado pelo que, medido por um padrão diferente, parece constituir uma forma de dar livre rédea às paixões de tortura de outras pessoas (idem)", trata-se, porém, de novo equilíbrio entre as coerções externas e internas. A redução do medo produzida pela monopolização da força física pelo Estado permite cadeias de interação mais longas e ampliação das formas de dependência, reforçando a modelação das ações por um superego diferenciado e estável. Nesse sentido, Elias não indica apenas uma conexão entre códigos de sentimento e a formação do Estado, mas uma relação particular que tem como elemento central a estabilidade e uma recusa compulsiva dos traços da natureza animal. O processo civilizador seria uma substituição de compulsões: troca-se a compulsão da natureza, o medo, pela compulsão do autocontrole.

Assim, as formas de civilidade são uma sedimentação social das regras pelas quais "as pessoas conseguem satisfazer suas necessidades animais elementares, sem reciprocamente se destruírem, frustrarem, humilharem ou de algum outro modo causarem repetidos danos umas às outras em busca dessa satisfação" (ELIAS, 1997, p. 42), principalmente através da preponderância da autocoação ou autocontrole sobre as coações externas. É importante destacar: (i) o fato de que o estabelecimento desses padrões pressupõe a superação das necessidades mínimas para sobrevivência (ii) e, consequentemente, a influência do ethos aristocrático nesse processo, em que o caráter de "boa sociedade" vai interferir na formação das classes ou nação.

Desse modo, Elias relacionou os problemas da violência e formação do Estado à produção de um habitus que se desenvolve no seguinte sentido: 
quanto maiores as redes sociais de interdependência, maior a mudança na relação entre controles exteriores e autocontrole, favorecendo este último. O controle e pacificação de largos territórios aumenta as possibilidades de identificação ao fortalecer o sentido de confiança, ao mesmo tempo que permite o desenvolvimento de controles impessoais. Os indivíduos precisam coordenar suas ações ou prestar mais atenção nas ações de outros, acostumando-se a adequar suas ações a interesses de longo prazo, necessitando controlar mais sistematicamente suas pulsões. Na base dos processos de racionalização da experiência está uma mudança na economia das emoções, em que o autocontrole se torna um elemento central para subjetivação e mediação das interações.

\section{Sociologia Figuracional e Sociologia das Moralidades}

Os problemas teóricos da sociologia figuracional se aproximam de uma sociologia das moralidades: a tensão entre práticas morais e discurso universalista; a relação entre emoções e valores; o conflito entre etiquetas e códigos e a substância ética, etc. Porém, com exceção das análises específicas sobre pânico moral (ROHLOFF, 2013), essas discussões parecem continuar seguindo o modelo eliasiano, que sobrepõe emoções e valores morais sem operar muitas distinções. Todavia, a partir de algumas leituras contemporâneas sobre o problema da civilidade, é possível perceber traços de um modelo de pesquisa sociológica importante para o estudo da vida moral.

Stephen Mennell (2007) e Eiko Ikegami (2005) são exemplos de como a pesquisa sociológica contemporânea sobre a civilidade e os processos civilizadores podem ser incorporados à sociologia das moralidades. Em The American Civilizing Process, Stephen Mennell (2007) desenvolve uma análise do processo civilizador americano. O ponto mais geral a se destacar é como o trabalho com os dados da história americana produz ênfases e sentidos particulares para o sentido de civilizador. Por exemplo, o autor destaca a centralidade dos mercados na imposição de controle e o papel do American dream nas formas de disciplinamento e autocontrole, ao mesmo tempo que destaca a permanência da religiosidade e de um sentido de altruísmo que identifica a experiência americana - operando tanto nas relações interpessoais quanto nas políticas imperialistas. É interessante destacar como o sentido de uma civilidade norte-americana aparece marcada por ambiguidades (imperialismo, armas, desigualdade racial etc.), ao mesmo tempo que projeta 
entre os atores um sentido de permanência, como se sua conexão entre valores e política fosse universal e imutável.

No entanto, o melhor modo de confrontar a perspectiva de que a teoria dos processos civilizadores apenas se adapta ao estudo de sociedades europeias é o trabalho da socióloga Eiko Ikegami. Ao estudar a era do shogunato Tokugawa no Japão (1603-1876), a autora analisa como associações de arte e poesia começam a organizar e conectar pessoas dos mais diferentes backgrounds e, a partir disso, como o surgimento de uma civilidade ordenada em termos da beleza ou de uma estética pública estava relacionada à formação do Estado japonês - a beleza e leveza dos gestos operou como um importante mecanismo de controle no Japão (IKEGAMI, 2005, p. 345).

Para Ikegami, a civilidade é vista como uma "tecnologia ritual" (idem, p. 28) estabelecendo situações de confiança e "quase-confiança" entre estranhos, ajudando a diminuir os custos das interações (idem, p. 49) e, especialmente, como essas formas de confiança não são naturais dos mercados e precisam ser sistematicamente construídas. De modo geral, o argumento desenvolvido pela autora diz respeito ao estilo distintivo da cultura disciplinar japonesa, suas rotinas estéticas, seus sentidos de aproximação e irmandade que não podem ser descritos como repressão, ao mesmo tempo que foram fundamentais para garantir a transição para os modos capitalistas de organização.

Esses exemplos não apenas sugerem a superação das críticas iniciais à sociologia figuracional, mas apontam, principalmente, para pesquisas que desenvolvem as conexões entre os modos de civilidade e os valores morais. Isso não se dá apenas naquele sentido mais genérico de que as boas maneiras são vistas como um ramo da moralidade (THOMAS, 2018, p. 18), mas, principalmente, no modo como os padrões de civilidade revelam as redes de interação e processo de hierarquização e significado entre indivíduos.

\section{Foucault e as técnicas de si}

Os últimos trabalhos de Michel Foucault se notabilizam, ao menos, por dois deslocamentos peculiares se comparado aos seus livros e análises anteriores. $\mathrm{O}$ primeiro é seu recuo temporal para a Antiguidade greco-romana e para os primeiros séculos do cristianismo, indo do século IV a.C. aos séculos II e III da era cristã. O segundo, mais crucial para os objetivos deste trabalho, foi sua preocupação mais intensa e direta com respeito ao papel da experiência moral para a análise e compreensão dos modos de subjetivação através dos quais, no 
Ocidente, os seres humanos se tornaram objetos de saber e poder para os outros e para si mesmos.

Os livros L'usage des plaisirs e Le souci de soi, ambos publicados em 1984, um pouco antes da prematura morte de Foucault, buscam entender como a atividade sexual foi constituída enquanto "problema moral"; são estudos, podemos dizer, acerca das moralidades dos prazeres ${ }^{8}$. Essa reorientação da problemática de pesquisa exigiu de Foucault lançar mão de um novo eixo de análise, qual seja, a subjetividade. Os volumes subsequentes a La volonté de savoir inauguram, de maneira mais acabada, um novo programa de investigação na trajetória filosófica de Foucault: o estudo dos modos de subjetivação enquanto práticas de autoconstituição.

\section{Moral e técnicas de si}

Nos textos antigos que formam o material histórico desses livros, Foucault se depara com uma série variada de práticas e exercícios que os indivíduos aplicavam sobre si mesmos, tais como: autoexame da consciência, retiros, exercícios de resistência diante de prazeres, correspondências para si e para os outros, meditação, provações físicas de abstinência, anotações e interpretações dos sonhos, passeios reflexivos, penitências públicas, confissões de faltas, entre outras.

A história do Ocidente é rica em práticas como as listadas. E, ao longo dos séculos, elas não somente receberam nomes diversos como, também, se fizeram presentes nos mais diversos campos da experiência social e de conhecimento das sociedades ocidentais: da filosofia à religião, da ciência ao Estado e suas mais diversas instituições e aparelhos. Foucault as intitula "técnicas de si" e as concebe como práticas de subjetivação e constituição do sujeito. É com esse conceito que ele busca explorar essa dimensão ativa da constituição do sujeito, que ele enxerga como fundamental na experiência moral dos prazeres no mundo grego clássico e no mundo cristão primitivo.

Por técnicas de si, ele entende, portanto, uma forma de atividade, a um só tempo, prática e reflexiva, em função do qual os indivíduos tentam organizar,

\footnotetext{
8 Respectivamente, o segundo e terceiro volume da História da sexualidade. Enquanto $O$ uso dos prazeres concentra-se na moral sexual no mundo grego clássico entre os séculos IV e III a.C., o volume $O$ cuidado de si, por sua vez, abrange no mundo greco-romano da época imperial nos dois primeiros séculos da era cristã a reelaboração dessa moral em termos de uma cultura de si; e, por último, o volume As confissões da carne trata da problematização da atividade sexual nas práticas ascéticas do cristianismo nos séculos IV e V da nossa era.
} 
com determinada regularidade, racionalidade e motivação, suas condutas e comportamentos, fixando para e sobre si mesmos determinados fins e meios com o objetivo de produzir um modo de ser específico. Essas técnicas consistem em práticas, exercícios e operações concretas por meio das quais os indivíduos conformam um princípio de ação sobre o seu modo de ser no sentido de determinarem-se como sujeito moral de suas condutas (FOUCAULT, 2014a).

Como conceito, as técnicas de si concernem às formas e modalidades históricas que estruturam a constituição do sujeito como sujeito moral de suas ações. São técnicas de autoformação e autoconstituição criadas e encontradas nas culturas e sociedades humanas por meio das quais indivíduos e grupos aderem e se esforçam para produzir e alcançar certos modos de agir e de ser valorizados, isto é, expressivo do cultivo de certas virtudes, traços, maneiras, conduta, caráter. Segundo Foucault, o que chamamos de "moral" não se restringe a um campo de atitudes ligado a um conjunto de regras e valores. A moral implica também "as formas e as modalidades da relação consigo através das quais o indivíduo se constitui e se reconhece como sujeito", campo de práticas e relações analiticamente distinto dos princípios e códigos morais aos quais está relacionado (FOUCAULT, 1984, p. 10).

O potencial heurístico e metodológico do conceito de técnicas de si reside nos deslocamentos e precisões analíticas que ele propõe para o pesquisador interessado nas moralidades. O primeiro deles diz respeito à abertura de um novo campo sociocultural de experiência, com seus discursos, tecnologias e práticas, para o estudo da moral, qual seja, a experiência e as relações do sujeito consigo próprio.

Esse escopo, com efeito, não é o dos códigos de valores e regras, como já dito. Não se trata também dos atos e das posturas efetivas, mas sim a forma particular de relação consigo mesmo que os indivíduos buscam e precisam instaurar para conduzirem moralmente a si mesmos em referência aos elementos normativos que formam a moralidade, pois "uma coisa é uma regra de conduta; outra, a conduta que se pode medir a essa regra. Mas, outra coisa ainda é a maneira pela qual é necessário 'conduzir-se'" (FOUCAULT, 1984, p. 26).

É sobre esse nível relacional entre subjetividade e moralidade que Foucault intitula "ética" que de fato o filósofo francês assenta o que estamos sugerindo como sua abordagem da moral. Aqui, ao nosso ver, reside a originalidade e a força foucaultiana no tratamento do tema da moral. Essa abordagem da moral, mais atenta às formas particulares de relação consigo do que às interdições e regras, suscita, a nosso ver, relevantes ganhos analíticos. 
No volume II da História da sexualidade, por exemplo, a análise comparativa entre a moral sexual greco-romana e a moral sexual cristã ganha um novo sentido e interpretação sob o ângulo das técnicas de si. Um sentido que é não o da oposição simplificada entre uma moral supostamente mais tolerante e liberadora ("paganismo") e outra mais regrada e repressiva das condutas sexuais (cristã). Assim como, tampouco, é o da mera continuidade das preocupações e prescrições, muito embora, aliás, contrariando o senso comum douto, tal continuidade exista no que se refere à persistência de alguns temas, tais como natureza do ato sexual, a fidelidade monogâmica, as relações homossexuais e a importância da castidade.

O que Foucault constata a partir da perspectiva das técnicas de si é que entre a austeridade sexual do mundo "pagão" e a austeridade sexual do mundo cristão, a descontinuidade que salta aos olhos não está ao nível do código e suas prescrições, mas sim nas práticas e sentidos das relações consigo que conformam a experiência moral do sujeito. Nos gregos, a relação consigo não se encontra normatizada em um código de condutas obrigatórias e universal, ao qual cada um e todos devem se submeter. Também os sentidos éticos e as preocupações morais que animam técnicas de si gregas visam a algo diferente da "decifração de si" e da "renúncia de si" como condições e provas da formação de um sujeito merecedor e purificado diante de Deus, característico da experiência moral cristã da "carne".

A moral sexual grega define-se por um projeto de cultivo do autodomínio que é mais de ordem facultativa, de uma decisão aristocrática em seguir "um princípio de estilização da conduta" para fazer da existência uma obra bela e realizada. Se ela também se defronta com as forças e perigos dos prazeres do corpo e das paixões da alma, é para moderá-las para alcançar um "domínio de si", um "estado de tranquilidade", para se tornar "senhor de si" (modos de ser, ethos). Ao invés do nomos, da lei, uma techné, uma arte de viver, um asceticismo autoatribuído na relação que o sujeito mantém consigo. Em vez de uma moral única, "morais" de grupos, morais como éticas e estilos de vida de grupos (FOUCAULT, 1984).

Como podemos concluir, as técnicas de si têm a ver, portanto, com a produção de um sujeito moral. Elas são parte de um processo complexo de subjetivação moral e que demanda, para produzir uma transformação de si mesmo em uma subjetividade moral, ocupar-se consigo mesmo. Em outras palavras, um engajamento moral e prático do indivíduo com sua conduta, maneiras, hábitos, sentimentos, aspirações para se autoproduzir. Para ilustrar a complexidade desse processo, isto é, a diversidade de aspectos envolvidos 
nesse nuançado trabalho dos indivíduos sobre eles próprios para adequar a conduta à regra moral, vejamos, por exemplo, como uma ética sexual austera pode ser alcançada e cultivada, ela:

(...) pode ser praticada por meio de um longo trabalho de aprendizagem, de memorização, de assimilação de um conjunto sistemático de preceitos e através de um controle regular da conduta, destinado a medir a exatidão com que se aplicam essas regras; pode-se praticá-la sob a forma de uma renúncia brusca, global e definitiva aos prazeres; como também sob a forma de um combate permanente, cujas peripécias - até os fracassos passageiros - podem ter sentido e valor; ela pode também ser exercida através de uma decifração tão cuidada, permanente e detalhada quanto possível, dos movimentos do desejo, sob todas as formas, mesmo aquelas mais obscuras sob as quais ele se oculta (FOUCAULT, 1984, p.27).

Essa variedade de formas e meios se deve ao fato de que "a relação consigo é estruturada como uma prática que pode ter seus modelos, suas conformidades, suas variantes, mas também suas criações" (FOUCAULT, 2014 b, p. 223). Estamos longe, com efeito, de um solipsismo ou um domínio da experiência humana aberto unicamente à fenomenologia filosófica e à psicologia profunda. Como já destacado, trata-se da produção de um ethos, de um modo de ser característico culturalmente valorizado, só que, no entanto, abordado para além da mera internalização das normas e valores externos. A ideia de técnicas de si incorpora e exige a agência moral dos indivíduos sobre suas vidas, práticas e sua relação com o mundo.

\section{Técnicas de si e poder}

Já na descrição das práticas de si na sociedade grega clássica e na cultura grecoromana, Foucault é sensível ao inter-relacionamento e aos elos destas com as relações de poder. As técnicas de si da ética clássica do uso dos prazeres estão revestidas e situadas em condições políticas e em lógicas de dominação e desigualdade. No caso da moral sexual dos gregos, elas são, explicitamente, atividades de e para uma aristocracia de homens livres, para a relação "entre o exercício de sua liberdade, as formas de seu poder e seu acesso à verdade". Trata-se de uma moral viril, assentada, escreve o filósofo, "num sistema muito duro de desigualdades e de coerções - em particular a respeito das mulheres e dos escravos". (FOUCAULT, 1984, p. 219). 
Também sua análise da epimeleia heautou, da ética helenística do cuidado de si, discorre acerca de como esse princípio de ação moral para se alcançar o bom e justo governo de si é, com efeito, entendido pelos gregos, sobretudo por Sócrates, e pelos romanos, como condição prévia para governar os outros. Sem ser capaz de se autogovernar, de cuidar de si, não se pode aspirar a governar os assuntos da polis. Por isso, o asceticismo moral do cuidado de si, com suas técnicas e exercícios, fazem parte, a um só tempo, do exercício moral daquele que se quer dominar a si mesmo e da paideia, do homem livre que pretende ser útil para a cidade (FOUCAULT, 1984, p. 70).

Portanto, pensar nas técnicas de autoformação do sujeito moral é pensar em poderes, nos elos e vínculos que os reúnem em determinadas relações de forças, que os condensam em instituições, saberes, discursos, regras, estratégias. Foucault está longe de os ignorar. Pelo contrário, ele os toma como imprescindíveis para o entendimento dos significados dos usos das técnicas de si e da singularidade histórica do modo de subjetivação moral dos sujeitos da antiguidade clássica. As práticas de estilização da conduta do ethos grego e greco-romano existem em conformidade - e devem dar testemunho de - com o status e a posição dominante numa economia particular de poder. O ethos de domínio de si, escreve Foucault,

(...) implicava um vínculo estreito entre a superioridade que se exerce sobre si próprio, aquele que se exerce no contexto da casa, e, enfim, aquele que se exerce no campo de uma sociedade agonística; e era a prática da superioridade sobre si que garantia o uso moderado e racional que se podia e devia fazer das outras duas. (FOUCAULT, 1985, p. 101).

No entanto, é na subjetivação do sujeito moral no cristianismo que a interação e interdependência entre as técnicas de si e as técnicas de poder se revelam de maneira ainda mais proeminente. Com o cristianismo, as técnicas de si estão integradas ao exercício de um tipo de poder peculiar, o poder pastoral. Neste, a sujeição é construída através da produção de uma forma de subjetividade intensamente preocupada e "alertada sobre suas próprias fraquezas, suas próprias tentações, sua própria carne..." (FOUCAULT, 2006b, p.71).

A partir da descrição das práticas espirituais monásticas, Foucault identifica no advento do cristianismo a emergência de uma nova matriz de individualização e uma mutação da orientação e sentido do "cuidado de si grego". Essas mudanças, assim busca demonstrar Foucault, estão estreitamente relacionadas 1) às obrigações morais estritas de verdade, 2) às práticas de si que 
o cristianismo, como uma religião de salvação e uma religião confessional, impõe para os indivíduos e, por fim, 3) à sociogênese do poder pastoral no Ocidente.

Além das obrigações de fé, de dogma, de reconhecimento das autoridades eclesiásticas e de certos livros como fonte de verdade e revelação, o cristianismo se caracteriza, também, por duas exigências morais decisivas: a obrigação de conhecimento de si e a obrigação de confissão de si para os outros. No cristianismo, solicita-se que cada um "se dedique a descobrir o que acontece em si, que reconheça os seus erros, admita suas tentações, localize seus desejos" (FOUCAULT, 2014a, p.287).

O conhecer-se a si mesmo cristão, em especial no modelo monásticoascético, significa reconhecer as tentações que se formam dentro da alma para, assim, se purificar e renunciar a si mesmo. Essas obrigações de verdade quanto ao descobrimento e à revelação de si são estruturadas como práticas, tais como a exomologese, a exagouresis, o ritual de confissão, o retiro, o jejum, a direção da consciência. Nelas, o fiel, o indivíduo, é conduzido, por meio de autocoações físicas, mentais e verbais, a produzir um saber sobre sua natureza profunda, sobre seus pensamentos, desejos, emoções, sensações, em suma, sua alma. Para ascender a um modo de ser purificado, o cristão deve reconhecer e revelar suas faltas, trazer à luz o verdadeiro ser do pecador que se é, o que, contudo, somente se obtém ao custo de uma exploração introspectiva profunda de si e de sua interioridade.

As técnicas de si cristãs são, portanto, técnicas de descobrimento, interiorização, vigilância, de exame e renúncia de si que tomam a carne, a concupiscência, essa matéria subjetiva, furtiva e vacilante atravessada de desejos e sensações perigosas, como o campo de batalha de si contra si e do si contra o mundo. Elas colocam em ação, portanto, mecanismos de poder e saber que os indivíduos exercem e alimentam sobre eles próprios e em relação a eles próprios. Para Foucault, a pastoral da carne cristã, com seus exercícios e atividades de autorrevelação, confissão e renúncia, engendra, com efeito, uma forma de relação consigo que é uma forma assujeitada: “A carne é a própria subjetividade do corpo, a carne cristã é a sexualidade presa no interior dessa subjetividade, dessa sujeição do indivíduo a ele mesmo, e este foi o primeiro efeito da introdução do poder pastoral na sociedade romana". (FOUCAULT, 2006b, p. 71).

As práticas de subjetivação moral do pastorado cristão não só constituem uma experiência moral de profundidade com o self, um "eu" profundo nas relações consigo, ao qual se deve descobrir, revelar e renunciar. Para Foucault, 
elas fazem e implicam mais: tais práticas ajudam a dar forma a toda uma tecnologia política de condução das condutas que é, a um só tempo, totalizante ("governar e conduzir o rebanho") e individualizante ("a alma de cada fiel, de cada pecador"), dada a relação de responsabilidade e obediência e o tipo de individualização que suas técnicas de direção da consciência instauram.

O ritual da confissão é, certamente, a forma mais acabada e sintética do funcionamento dessa tecnologia e de suas implicações de poder. $\mathrm{O}$ ato de confissão é um exame de si exaustivo sob a presença e a escuta de uma outra pessoa, que deve conhecer o que se passa no íntimo dos fiéis. Nesse ritual, o fiel confessante e o sacerdote confessor estão vinculados numa relação moral, que é, indubitavelmente, uma relação de poder. O primeiro tem a obrigação de produzir um discurso sobre si mesmo, sobre suas falhas, seus sentimentos, seus pensamentos, enquanto o segundo busca conduzir o confessante, a partir de seu saber e de sua posição de poder, a reconhecer a verdade de seu interior. A confissão é uma técnica de individualização conduzida, uma técnica de si para a produção sujeitada do sujeito moral.

Temos, assim, o que Foucault chama de "poder pastoral", um poder que é, como explica Foucault, um poder de "cuidado", pois se exerce sobre as pessoas para conduzi-las para modos de ser "purificados", "corretos", afastando-as de padrões de conduta "perigosos", "pecaminosos", "impuros". Trata-se mais de um poder de condução das condutas, de correção de modos de ser, do que um poder que estabelece leis e que se exerce sobre um território.

A pastoral cristã consiste num exercício de poder que opera por meio de técnicas de si, como a confissão. Não se trata de uma internalização mecânica de dogmas e normas morais de um sistema religioso. A pastoral cristã é um intenso e poderoso trabalho de subjetivação que objetiva nos indivíduos uma forma particular de relação consigo, abre um novo domínio e sentido da experiência da subjetividade: a constituição do sujeito se processa e se sustenta numa sujeição, no assujeitamento de si a um outro e a um código moral institucionalizado, que incita e prescreve padrões normalizadores de conduta, de sentimento e pensamento.

\section{Considerações finais}

Neste trabalho, apresentamos duas ferramentas heurísticas, colhidas nas obras e análises do sociólogo Norbert Elias e do filósofo Michel Foucault, civilidade e técnicas de si. Com elas, entendemos que a sociologia da moral contemporânea pode obter, em pesquisas empíricas e teóricas, importantes 
ganhos em termos de compreensão das relações entre moralidade, agência e poder.

Nos diversos trabalhos histórico-sociológicos de Elias, os códigos normativos e regulamentadores dos comportamentos e das emoções constituem uma chave de leitura fundamental para explicar as dinâmicas de poder e interdependências entre os indivíduos e grupos numa dada figuração social, assim como os processos de mudança. Esses códigos morais e as disputas e tensões inter e intragrupos que suscitam dão forma e conteúdo a instituições, valores, padrões de comportamento e sentimento, autorrepresentações, hierarquias de classes, lógicas de exclusão e distinção (ELIAS, 1993, 1994; ELIAS; SCOTSON, 2000).

Na sociologia eliaseana, os ethos e valores morais de grupos são ingredientes cruciais nas formas de racionalidade de repartição, apropriação e sentidos dos recursos materiais e simbólicos. Em linhas gerais, podemos afirmar que Elias aborda a moralidade enquanto uma lógica hierárquica de valores e emoções dos grupos em suas posições e disputas na distribuição de poder.

Por sua vez, Michel Foucault e seu projeto de uma "genealogia do sujeito na civilização ocidental" (FOUCAULT, 2006a, p. 95), isto é, de estudar os diferentes modos de constituição do sujeito nas práticas históricas, reservou à moralidade um lugar destacado. Especialmente em suas últimas obras, Foucault dedicou-se a examinar como os seres humanos constituem-se a si próprios como sujeitos morais, quer dizer, como agentes éticos de suas condutas e ações (FOUCAULT, 1995, p. 231).

Investigar a experiência moral do sujeito enquanto a formação de uma hermenêutica de si conduziu o filósofo francês a uma reorientação do enfoque de seus instrumentos teóricos. Em vez das técnicas de poder e saber de sujeição, Foucault passa a abordar, com mais ênfase, o que chama de "técnicas de si": os exercícios, as práticas e procedimentos prescritos, regras e pressuposições tácitas de éticas, manuais e modelos de vida e conduta que permitem constituir, fixar, manter e transformar a identidade do sujeito a partir de um trabalho de si sobre si mesmo (FOUCAULT, 1984).

De modo mais direto e sociologicamente mediado, tanto o conceito de civilidade como o de técnicas de si oportunizam um novo campo de historicidade dos valores e das normas quanto um novo eixo analítico para a sociologia da moral, a subjetividade e suas formas históricas de autorrelação para constituição do sujeito moral. Ampliam o estudo das experiências morais das pessoas e grupos para além dos discursos e princípios explícitos de justificação dos atores acerca de suas ações e das situações sociais em que estão 
inseridos. Ambos os conceitos, portanto, abrem a relação mediada dos indivíduos consigo mesmos, com sua subjetividade, emoções e atitudes, para o plano de uma análise sociológica orientada por duas coordenadas: 1) processos de mudança social via transformação e ruptura de grandes códigos e ethos, e 2) constituição do sujeito através de práticas morais vividas pelos indivíduos e grupos. Nesses autores, a moral existe como dimensão entrelaçada da experiência coletiva e individual dos seres humanos.

$\mathrm{O}$ que foi apresentado aqui consiste em uma primeira aproximação e discussão. Pretende-se, em trabalhos futuros, dar continuidade com maior grau de detalhamento teórico e empírico das categorias exploradas neste estudo, a fim de contribuir com o desenvolvimento de um programa eliaseano e foucaultiano de sociologia das moralidades.

\section{Referências}

ABEND, Gabriel.

(2013). What's New and What's Old about the New Sociology of Morality. In: HITLIN, Steven. VAISEY, Stephen (orgs). Handbook of the Sociology of Morality. Nova York, Springer, p. 561-582.

ALEXANDER, Jeffrey. (1987 jun). 0 Novo Movimento Teórico. RBCS. São Paulo, v.2, n.4, p.5-28.

BAUMAN, Zygmunt.

(1998). Modernidade e holocausto. Rio de Janeiro: Jorge Zahar.

BOLTANSKI, LUC., THÉVENOT Laurent. (1991). De la Justification. Paris: Gallimard.

BRIT0, Simone.

(2019). Menos política, mais eficiência: uma análise sociológica das práticas de auditoria e produção de sentidos morais no campo burocrático. Revista Brasileira de Sociologia, v. 7, p. 215-234.

(2011). Traçando os limites da Sociologia da Moralidade: uma perspectiva adorniana. Estudos de Sociologia. Recife, v. 1, p. 82.
ELIAS, Norbert; DUNNING, Eric.

(1992). A busca da excitação: esporte e lazer no processo civilizacional. Lisboa: Difel.

(1993). O processo civilizador: formação do estado e civilização. Rio de Janeiro: Jorge Zahar.

(1994). O processo civilizador: uma história dos costumes. Rio de Janeiro: Jorge Zahar.

(1997). Os alemães. A luta pelo poder e a evolução do habitus nos séculos XIX eXX. Rio de Janeiro: Jorge Zahar.

(1998) The Norbert Elias reader: a biographical selection. Oxford, Blackwell Publishers.

(2001). A sociedade de corte. Rio de Janeiro: Jorge Zahar.

(2005) Introdução à Sociologia. Lisboa, Edições 70.

ELIAS, Norbert; SCOTSON, John. (2000). Os estabelecidos e outsiders: sociologia das relações de poder a partir de uma pequena comunidade. Rio de Janeiro: Zahar. 
FASSIN, Didier.

(2011). Humanitarian Reason: A Moral History of the Present. Berkeley: University of California Press.

(2013). Enforcing order: an anthropology of urban policing. Cambridge: Polity Press.

FOUCAULT, Michel.

(1984). História da sexualidade 2 - o uso dos prazeres. Rio de Janeiro: Graal.

(1985). História da Sexualidade 3: 0 cuidado de si. Rio de Janeiro: Graal.

(1995). 0 sujeito e o poder. In. DREYFUS, H. \& RABINOW, P. Michel Foucault, uma trajetória filosófica: para além do estruturalismo e da hermenêutica. Rio de Janeiro: Forense Universitária.

(2006a). Sexualidade e solidão. In. Ditos \& Escritos: Ética, sexualidade e política. vol. V. Rio de Janeiro: Forense Universitária.

(2006b). Sexualidade e poder. In. Ditos \& Escritos: Ética, sexualidade e política. vol. V. Rio de Janeiro: Forense Universitária.

(20014a). As técnicas de si. In. Ditos \& Escritos: Genealogia da Ética, subjetividade e sexualidade. vol. IX. Rio de Janeiro: Forense Universitária.

(20014b). Sobre a genealogia da ética: um resumo do trabalho em curso. In. Ditos \& Escritos: Genealogia da Ética, subjetividade e sexualidade. vol. IX. Rio de Janeiro: Forense Universitária.

GIDDENS, Anthony.

(1989) A constituição da sociedade. São Paulo Martins Fontes

GUPTA, Akhil.

(2012). Red tape: bureaucracy, structural violence, and poverty in India. Durham: Duke University Press.

HITLIN, S.; VAISEY, S. (Eds.).

(2010). Handbook of the sociology of morality. New York: Springer.
(2013). The new sociology of morality. Annual Review of Sociology 39: 51-62

IKEGAMI, Eiko.

(2005). Bonds of Civility. Aesthetic Networks and the Political origins of Japanese Culture. New York: Cambridge.

LAMONT, Michele.

(1994) Money, Morals and Manners. Chicago. The University of Chicago Press,

(2000). The Dignity of Working Man. New York. Russel Sage Fundation.

MACINTYRE, Alan.

(2001). Depois da Virtude. Bauru: Edusc.

McCAFFREE, Kevin.

(2016). Sociology as the study of morality. In. ABRUTYN, Seth (ed.). Handbook of Contemporary Sociological Theory. Springer, p. 435-456.

MENNELL, Stephen; RUNDELL, John F. (org.)

(1998). Classical readings in culture and civilization. London and New York: Routledge

(2007). The American Civilizing Process. Cambridge and Malden: Polity Press.

RIFIOTIS, Theophilos; SEGATA, Jean (Orgs.). (2019). Políticas etnográficas no campo da moral. Porto Alegre: UFRGS.

ROHLOFF, Amanda.

(2013). Moral panics as civilising and decivilising processes? A comparative discussion. Politica y Sociedad, vol.50, n. 2, p. 483-500.

THOMAS, Keith.

(2018). In pursuit of Civility. Manners and Civilization in early Modern England. Massachussets: Brandeis University Press.

WERNECK, Alexandre; CARDOSO DE OLIVEIRA, Luís Roberto (Org.).

(2014). Pensando bem: estudos de sociologia e antropologia da moral. Rio de Janeiro: Casa da Palavra. 
WOUTERS, Cas.

(1986). Formalization and Informalization: Changing Tension Balances in Civilizing Processes. pp.1-19 in Theory, Culture \& Society, vol. 3, n. 2. London: SAGE.

(2004). Sex and Manners: Female Emancipation in the West 1890-2000. London: Sage.
(2007). Informalization: Manners and Emotions since 1890. London: Sage.

\section{Recebido em}

setembro de 2020

Aprovado em

março de 2021 